\title{
THE CONCEPT OF HYBRID MANUFACTURING FOR HIGH PERFORMANCE PARTS\#
}

\author{
K. Boivie ${ }^{1 *}$, R. Karlsen ${ }^{2} \&$ P. Ystgaard ${ }^{3}$ \\ 1, 2, 3 Department of Production Technology \\ SINTEF Raufoss Manufacturing AS, Norway \\ ${ }^{1}$ klas. boivie@sintef.no, ${ }^{2}$ roald. karlsen@sintef.no, ${ }^{3}$ pal. ystgaard@sintef.no
}

\begin{abstract}
The development of additive manufacturing technology (AMT) for metallic materials has reached a level where the processes are capable of producing complex geometries with industrial grade material properties. However, AMT is still hardly competitive with conventional (subtractive) machining with regard to production speed, accuracy, and surface quality. To address these limitations, AMT can be combined with subtractive manufacturing technology into a hybrid manufacturing system. This paper introduces the concept of hybrid manufacturing with examples from ongoing industrial case studies, and describes the requirements for the future development of an integrated hybrid manufacturing system.
\end{abstract}

\section{OPSOMMING}

Die ontwikkeling van byvoegende vervaardigingstegnologie vir metaal het die peil bereik waar prosesse in staat is om komplekse meetkundes te vervaardig met nywerheidsgraad materiale. Die tegnologie ondervind egter strawwe mededinging vanaf konvensionele masjinering ten opsigte van produksienetheid, akkuraatheid en oppervlakte-afwerking. Die twee mededingende metodes kan egter tesame gebruik word as ' $n$ bastersisteem soos getoon deur voortgaande industriële gevallestudies.

* Corresponding author.

\#This article is an extended version of a paper presented at the 2011 RAPDASA conference. 


\section{INTRODUCTION}

The rapid development of additive manufacturing technologies (AMT) for metallic materials over the last decade has made several alternative systems and materials available to the manufacturing industry. At present the number of available materials is somewhat limited, and the different systems have different characteristics and are therefore more suited for different applications. However, the achievable properties of products made by modern metallic AMT are highly comparable to products made by conventional manufacturing processes.

With accelerating demands for new and increasingly complex high-value products in the international manufacturing industry, there are a growing number of applications in which the limitations of conventional manufacturing technology will hamper innovation and development. Since additive manufacturing (AM) is not limited by the requirements for cutting tools, dies, and moulds to shape a material into the desired geometry, AMT enables the production of industrial-grade products with a freedom of geometry never seen before in manufacturing technology. This makes it well suited to respond to many of the challenges faced by the modern manufacturing industry. However, despite the progress and new possibilities, most of the manufacturing industry still hardly regards AM as a serious manufacturing process alternative.

There are several reasons for how this came to be. Additive processes were initially developed to produce physical models from CAD data; they were not developed as manufacturing tools, and there is no tradition of designing parts for production by AM. Also, there are no established technical standards for these processes, the materials, or quality management. Until the AM machines and material systems are developed for manufacturing applications, there will be limitations in the application of the technology and its output.

Another fundamental reason for the limited application is that building parts by AM is not cheap or "rapid" when compared with conventional machining; and since the cost increases with the building time and amount of material added to the part, the price of larger parts can be quite high. On the other hand, while the cost of conventional CNC machining increases with the amount of material removed, it is considerably faster in shaping massive objects, has a wider array of alternative materials, is a very familiar process, and is capable of producing parts with a precision and surface finish that is very different from those that can be produced by AM. One of the principal challenges in establishing AMT as a part of the industrial manufacturing system is to integrate the functionality of the AM processes with established manufacturing processes in a highly flexible hybrid manufacturing solution, in which the combined benefits of each manufacturing technology can be fully exploited.

\section{BACKGROUND: THE CONCEPT OF HYBRID MANUFACTURING}

The limitations of AM regarding surface quality and precision are well known. In order to combine the benefits of each manufacturing principle, several hybrid manufacturing solutions have been suggested - for example, those by Karunakaran [1], Kerbrat [2], Hu [3], Hedges [4], and LaserCusing. nl [5]. For many of the metal deposition systems - such as LENS (laser engineered net shaping) by Optomec [6], DMD (direct metal deposition) by POM [7], and EBFFF (electron beam free form fabrication) by Sciaky [8] - the balance between material deposition rate and surface quality is set so that most situations require a hybrid solution. These processes are used many times to produce a 'nearer to net shape' raw product that reduces the need for costly milling in difficult materials such as titanium and Inconel [4]. Other processes, such as CMB (controlled metal build-up) by Fraunhofer IPT in Aachen, have gone a step further (as reported by Beaman [9]), and integrated milling as a process sequence before the deposition of each new layer. This approach was commercialised by Albercht Röders for a while, although technical problems led to its withdrawal from the market. 
Hybrid manufacturing based on AMT has the potential to combine the design flexibility of additive processes with the precision and productivity of conventional manufacturing. This enables the manufacture of products that would be extremely difficult to produce through other methods at a competitive price. In addition, the freedom of design and the flexibility in implementing rapid design changes - which is characteristic of $\mathrm{AM}$ - enables a high degree of product customisation. Moreover, the additional possibility for variable material composition in the additive process makes it feasible to produce products with a higher performance than can be achieved with processes limited to a single material at a time. In the long term, products under development will not necessarily need to be viewed as a single entity, but rather as a series of features that can be produced in the most costand/ or time-effective way by hybrid manufacturing. This is more of a visionary possibility than a practical reality at present, and there are still many issues to be resolved before it can be realised. This paper investigates what would be required for the industrial implementation of hybrid manufacturing through practical case studies, and how these can be resolved in a highly flexible, integrated, hybrid manufacturing cell.

\section{HYBRID MANUFACTURING CASE STUDIES}

\subsection{Background}

Manufacturing products with higher performance than their conventional counterparts will naturally be more complex and demanding. In order to be competitive, the product has to offer a distinct advantage in performance and quality without having excessive cost or lead times compared with traditional products. This implies that the production system has to be flexible and high precision, as well as both time- and cost-efficient. For prototypes and tools, the combination of additive and subtractive processes to meet this challenge has been discussed in several papers [3, 10, 11, 12, 13]. For hybrid manufacturing to be accepted as an alternative solution, and to be considered for implementation in the established manufacturing system, the practical benefits have to be verified by relevant case studies. With this in mind, the objectives of the industrial case studies have been to:

a) verify the benefits of AM to relevant manufacturing industries;

b) evaluate present hybrid manufacturing practices; and

c) find the most important points for the development of an improved hybrid manufacturing system.

The case studies have been carried out as a collaboration between local Norwegian manufacturing companies and international partners to ensure that: a) conventional manufacturing is relevant for local Norwegian practice; and b) the practical aspects of AM and hybrid manufacturing are carried out according to state-of-the-art and established best practices.

\subsection{Inserts for injection moulding tooling}

\subsubsection{Inserts for a bracket to an office chair}

The bracket for this case study is a critical component in an office chair: it connects the chair lift with the seat, and therefor carries a heavy load. For this connection to have sufficient strength, the original solution included a machined piece of steel moulded into the bracket. To avoid this costly solution, a new design was developed in which the machined steel part was replaced by a steel washer and a thicker moulded wall. However, the thicker wall made the cooling of this section of the product critical for the process cycle times; and since the core insert for this section was also the injection nozzle - and therefore a hot spot in itself - the cooling of this core was a particular challenge. The original insert was made from Moldmax (a copper alloy tooling material), with inner cooling channels drilled in a finger pattern. This is the highest level of cooling that can be achieved with traditional tooling techniques; but this is not satisfactory for the new bracket design.

As an alternative case study solution, a new core was built by AM with parallel conformal cooling channels in an umbrella pattern (see Figure 1A). The cooling channels and the core 
were designed and made by ConceptLaser $\mathrm{GmbH}$ of Lichtenfels, Germany ${ }^{1}$, and then machined to the final geometry by a Norwegian toolmaker (see Figures $1 \mathrm{~B}$ and $\mathrm{C}$ ).
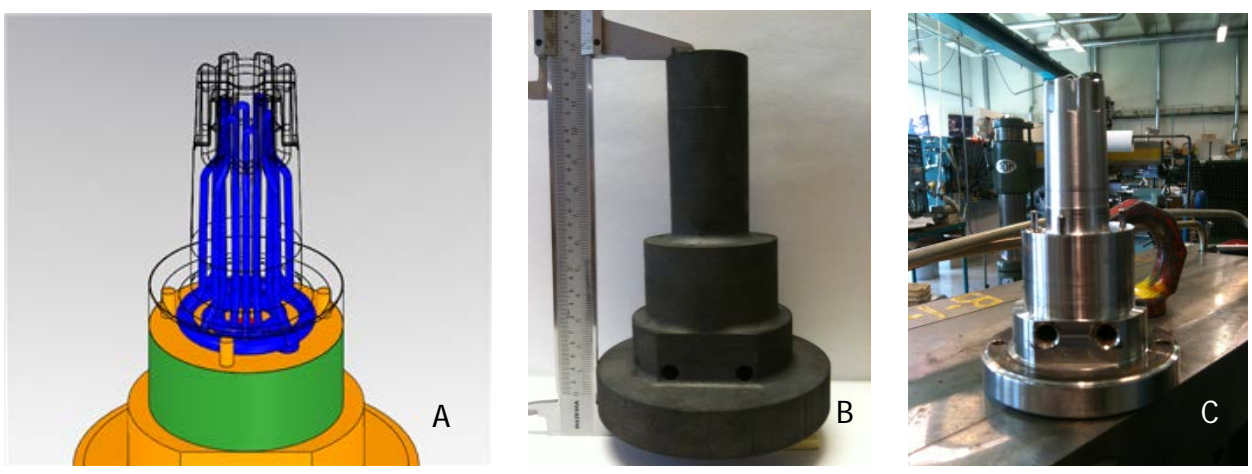

Figure 1: Injection moulding core with conformal cooling channel.

From left: (A) conformal cooling channel design; (B) core prior to machining ${ }^{2}$; and (C) the finished tool after testing.

The practical testing of injection moulding with the new conformal cooling core resulted in a reduction in the cooling time from 70 seconds (original tool, original bracket design with original material thickness) to 48 seconds (conformal cooling core, new bracket design with increased material thickness). Simulations have indicated that the increased material thickness of the product would increase the cooling time by about 25 seconds using a conventional core. So by integrating conformal cooling with a critical core in this tool, the total cycle time was reduced by $20 \%$ instead of the expected increase of $20 \%$ This is a significant improvement in the performance of the tool, achieved by the application of hybrid manufacturing. Yet, even if the cost of machining the new core was about the same as for the original core, the additional cost for AM made the total cost of the new core double that of the original. However, unlike the original core, the production of the new core was carried out in two different locations - one clear reason for a significant increase in the lead time for the insert. Even so, it is hardly possible to draw any conclusions about the extent to which this has been caused by either the additional AM process, or the increased complexity of information flow and logistics arising from the separate production locations.

\subsubsection{Manifold for compressed airbrake system}

The manifold in this case study has four slots for push-in air couplings fixed on a base plate, used to mount the manifold on an air tank (see Figure 2). The design is highly controlled by customer requirements, and does not entirely follow best practice for parts produced by injection moulding. This has made production of the manifold difficult, and during injection moulding there is significant warpage in the base plate. The original solution was to keep the parts in the mould for 30 seconds, remove them while they were still a bit soft, and then manually place them in a fixture to cool in ice water for 90 seconds (see Figure 2).

\footnotetext{
${ }^{1}$ ConceptLaser is a producer of metallic AM systems with a strong background in the injection moulding and tooling industry, and with experience and expertise in designing conformal cooling systems for injection-moulding tool inserts as well as practical hybrid manufacturing solutions.

2 Some modification in the original design occurred during production of the insert: the length of the middle section was increased, and the holes for the cooling water were moved further away from the bottom plate to facilitate assembly of the cooling system. The picture in Figure 1B shows the original design, and the picture in Figure $1 \mathrm{C}$ is of the final insert.
} 

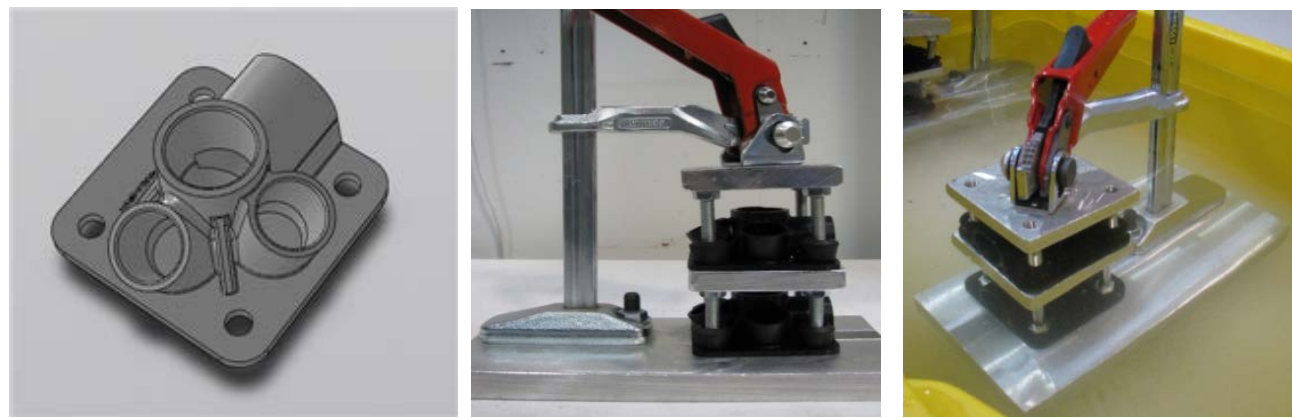

Figure 2: Manifold for compressed air couplings, injection moulded in a double cavity tool, and the setup for warpage correction. This solution has a two minute cycle time, and requires a crew of three operators and the use of a water tank.

Research has shown that conformal and directed cooling can reduce both warpage and cycle times [14]; and one aim of this case study was to investigate this possibility. This is a double cavity tool, in which each cavity has three sliders and five cores. For the case study, a new set consisting of one cavity with sliders and cores was manufactured with integrated conformal cooling. As in case 1 , this new tool was built using a hybrid manufacturing procedure: the base parts were milled from Orvar Supreme tool steel [15] at a local toolmaker company, then sent to ConceptLaser for AM of the remaining part - including the section with conformal cooling - and then returned to the local toolmaker for machining, grinding, and polishing to the required precision and surface quality.

During test runs, the new tool showed a significant improvement in cooling, although the problem with warpage remained. However, if the part was kept in the tool until it cooled enough for the plastic to reach a rigid state, the parts came out with a satisfactory flat base plate. This made it possible to omit the fixture and water bath, while reducing the crew to one operator. However, it increased the cycle time to five minutes. Clearly, despite the advantages of integrating conformal cooling, this cannot totally compensate for the challenges built into the design of the product.

With hybrid manufacturing, both the number of process steps and the complexity of the information flow have been increased, resulting in a disproportionate relationship between the processing lead time and the actual production time. Some very practical issues arising from this approach to the hybrid production of tooling inserts were observed. For example, increasing the number of process steps and using a greater variety of machines multiplies the number of setups necessary for each part. This requires additional safety margins and offsets to be added to the part geometry during the early process steps, which in turn increases the amount of material that must be removed in the finishing machining. Even if the production of this mould is carried out at the same location, the setup time and labour costs required at each process step will be substantial. If hybrid manufacturing is to become a more competitive part of an industrial production system, a more integrated process solution is needed.

\subsection{Multi-material punch tool}

The third case study is an ongoing activity that focuses on the prolonged lifetime of a punch tool. The punch is used for making holes in aluminium profiles for the automotive industry. Critical issues are the abrasion and wear on the tool edge, followed by crack formation in the cup. The current material in the punch is tool steel: H13 or DIN W.nr.1.2344, HRc 52, (corresponding to Orvar Supreme [15]). 

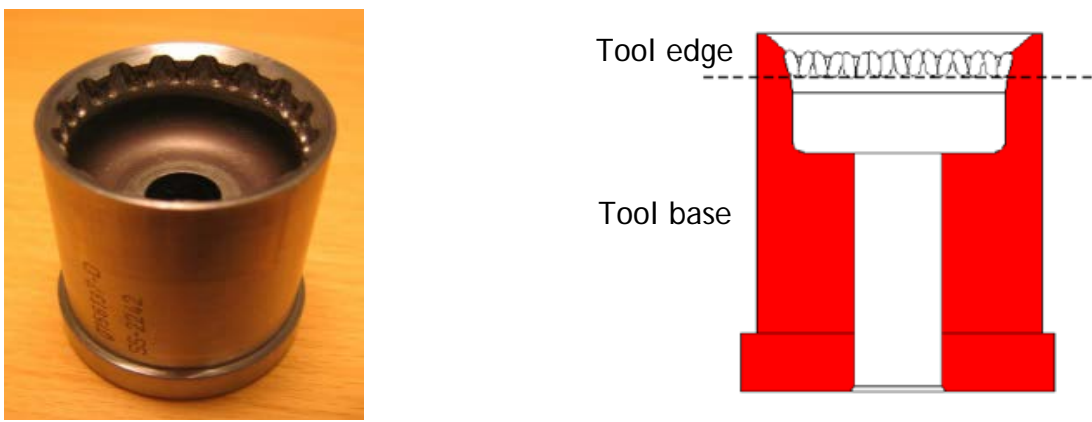

Figure 3: Punch tool and schematic of the intended solution: A tool base that is machined from the original tool steel material, with a tool edge made of CCW+ (a work hardening Stellite variety), built on to the tool base.

The new tool is made by hybrid manufacturing (see Figure 3 ). First, the tool base is made by machining in tool steel Orvar Supreme [15], which is heat treated to HRc 48. The edge material, CCW+ (a work hardening variety of Stellite), is added directly to the base piece using the LENS AM process. Again, the machining is carried out by a local toolmaker company; and the LENS AM is done by the South Dakota School of Mines and Technology in Rapid City, SD, USA, which has long experience with this technology. The hardness of CCW+ directly after deposition will be in the HRc mid-40s; but since this is a work hardening material, it will reach the required hardness with use. This case study is still in progress, and at the time of writing (J anuary 2012), a set of tool bases had arrived from South Dakota after CCW+deposition by LENS, and were being prepared for machining to final shape at a local toolmaker. There is no previous experience with the LENS deposition of this particular tool steel, so a series of primary deposition tests have been aimed at finding the correct parameters and verifying that no cracks are formed in the heat-affected zone. Since neither hardened tool steel nor CCW+ is favourable for machining, it has been made an objective to bring the LENS processing as close as possible to the final measurements (see Figure 4).
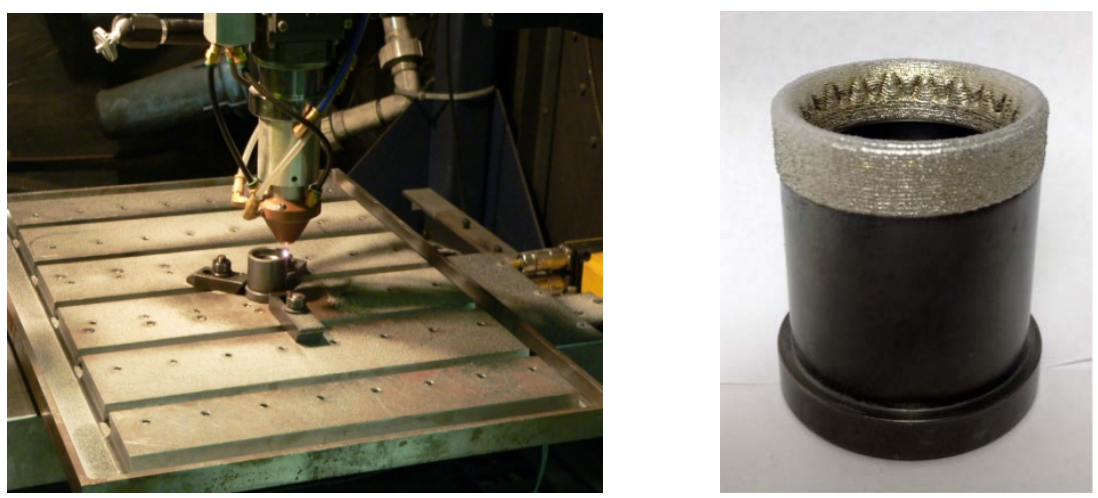

Figure 4: Setup for the deposition of the tip material in the LENS machine, and an example of a tool base with a deposited near net-shape tool edge.

Even if the graded material punch tools have not been tested for performance, and so cannot be shown to benefit AM application at this stage, it is still possible to draw some conclusions about integrated hybrid manufacturing. It is unlikely that the final net shape will be reached with this process, so some final machining will be necessary. However, even if the work table for the LENS is similar to a conventional machine tool, the clamping for these has little precision, and a substantial manual operation is required to mount and position the work piece and to find the zero point coordinates for the AM building. Alternatively, a significant oversize in the tool base would be required, and thus significant final machining. 


\subsection{Aeronautical component: Complex geometry}

The fourth case study is a complex aluminium part for an aerospace application (see Figure 5). This is just an example part: it is put together from different parts with examples of features that are relevant to the partner company, but there is no real application for this specific product. The most important points to demonstrate have been:

- the ability to produce complex geometries;

- the possibility of combining several parts in one piece;

- the possibility of saving weight by building a hollow structure; and

- satisfactory material properties.

In practical applications, geometries similar to this are put together from three different components. The route selected for the hybrid manufacturing process was to build a close to net-shape part with AMT using the ConceptLaser's power bed process, followed by CNC finishing machining on critical surfaces.
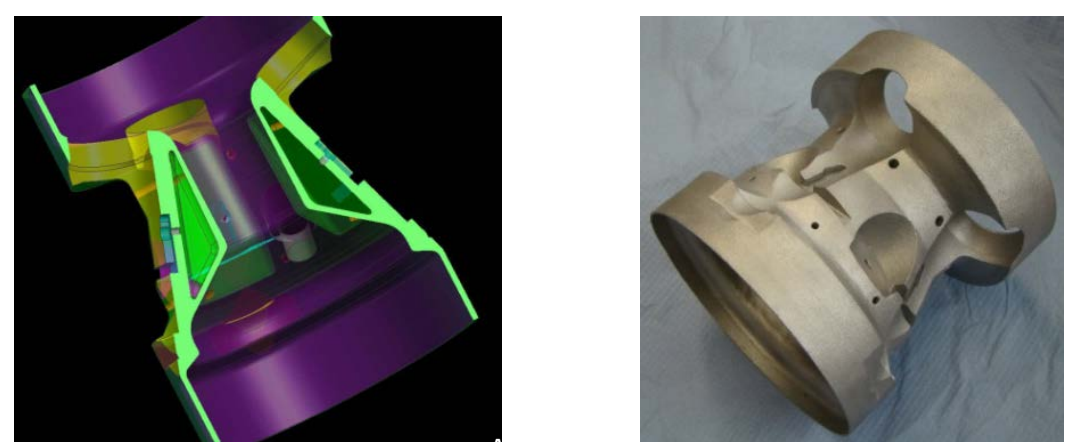

Figure 5: (A) CAD model of the case study geometry, and (B) the manufactured part

Sample test bars were built separately, and material testing found the properties to be satisfactory; however, more testing would be advisable when manufacturing parts for a fullscale flying application. The ability to produce complex structures of what traditionally would have been several components is a significant advantage with AMT; and since this type of product is rarely produced in large quantities, there would be no advantage in applying the principles of mass production. Moreover, the hollow wall sections not only save weight in the product, they also leave room to build more functionality into this piece. Thus hybrid manufacturing not only makes it possible to improve the performance of this type of product, it also enables new types of products to be evolved. However, new types of products and new manufacturing technologies will also require new design principles another topic that will have to be developed for further integration of AMT as an industrial manufacturing technology.

For the finishing machining of this part, it was noted that complex geometries such as this may have critical surfaces that require machining in many directions. At the same time, the geometry itself could impose a certain building orientation on the AM system. There will clearly be a need for optimisation between the part orientation for AM building and the part orientation for finishing machining. This is a type of geometry that could only be built in a powder bed AM system; and such systems require support structures that anchor the part during building, and that support big overhangs. Since the support structure has to be removed - preferably with as little manual labour as possible - this is something that will have to be taken into account when this type of complex geometry is to be produced by hybrid manufacturing as part of an industrial manufacturing system.

\section{THE HYBRID MANUFACTURING CELL}

The industrial case studies have shown that hybrid manufacturing can add substantial value to high performance parts. Still, conventional milling and AM building are two fundamentally different processes, with fundamentally different process requirements that 
must be fulfilled before the work piece can enter the next process step. It has therefore been concluded that having the entire hybrid manufacturing process in a single machine would not be practical. A more flexible solution would be to integrate the workflow of two or more independent manufacturing machines into a hybrid manufacturing cell. The most beneficial combination of AMT and conventional manufacturing systems would depend on what type of products and product geometries are to be produced in the hybrid cell. From the clear benefits shown in the injection moulding case studies, the primary objective for the development of the hybrid cell would be tooling inserts for injection moulding.

The basic principle of the hybrid cell is to have integrated cooperation between an AM machine (in this case a ConceptLaser M2 Cusing machine (M2)) and a CNC milling machine (in this case a Deckel-Maho 5-axis milling machine (DM)), in which each technology is used to shape that part of the final tooling insert geometry for which it is most advantageous.

For a typical injection moulding insert, this means that a base part would be milled from a block of raw material that has good milling properties and is compatible with AM building conditions. In the primary milling operation, special attention would have to be given to ensuring that the top and bottom surfaces are parallel, and that the surface quality of the upper surface fulfils the requirements of serving as a substrate during the AM building. The base part will then be moved to the M2 machine in which the section of the insert with the more complex geometry (typically the conformal cooling) is added to the base part. Finally, after the AM building has been completed, the raw product will be returned to the DM machine for finishing machining to the desired dimensions and surface quality. The typical workflow for the production of hybrid manufacturing inserts is shown in Figure 6.

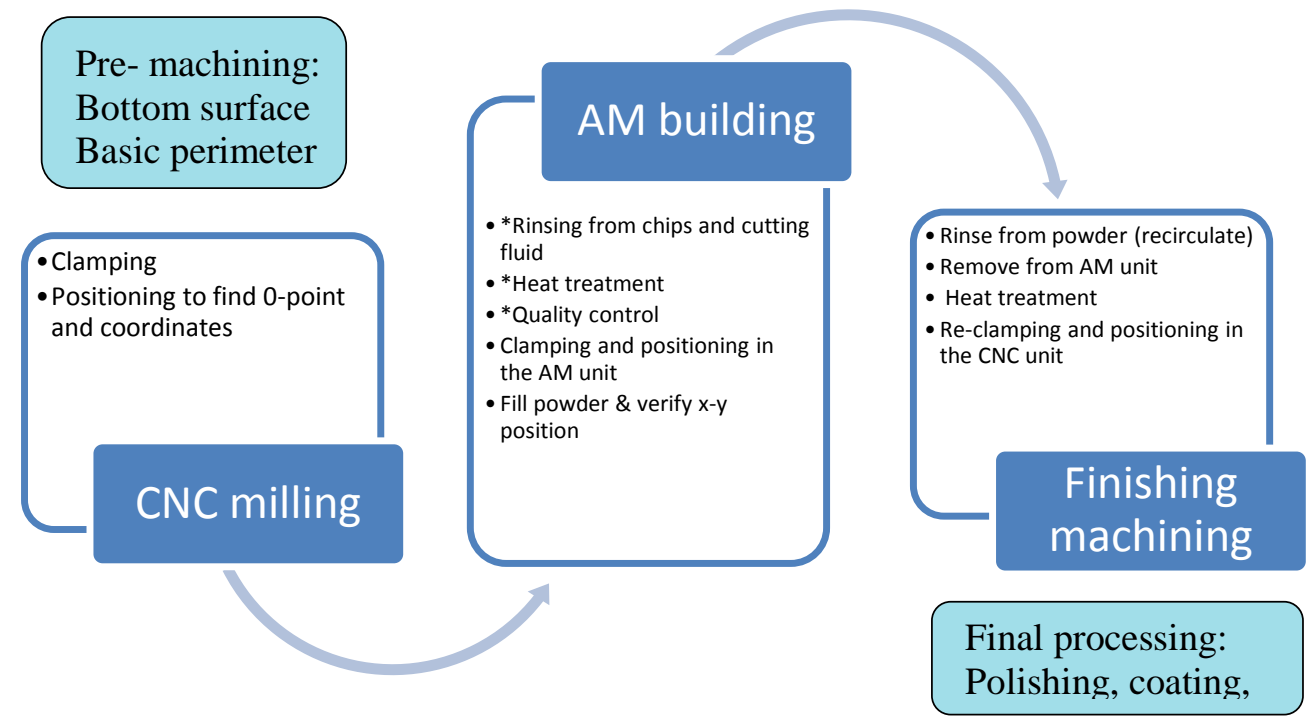

\section{Figure 6: Typical workflow for the production of injection moulding inserts in the hybrid manufacturing cell. Operations marked with * are best kept to a minimum or, if possible, avoided altogether.}

For the best possible precision and repeatability in the positioning operation, to facilitate the mounting of the work piece in each machine unit and to minimise the need to add offset material as a safety margin (thus minimising the required final machining), a standard pallet and chuck system is used to clamp the part. The M2 has an EROWA power chuck [16] integrated into the build chamber (see Figure 7), so this system has also been evaluated as a clamping system for milling. The investigations have concluded that the precision and repeatability of the positioning with the EROWA system are within the tolerances for the hybrid cell. In combination with a measuring probe integrated into the $D M$, this will enable sufficient precision in the positioning to maintain the quality of the 
product throughout the hybrid manufacturing process. However, a side effect of conventional milling observed during these experiments was the flooding of cutting fluids over the work piece and penetration through both the pallet and chuck. This is not a problem for milling or for the equipment, but the cutting fluid would pollute the powder material and process chamber during the AM process (see Figure 7).
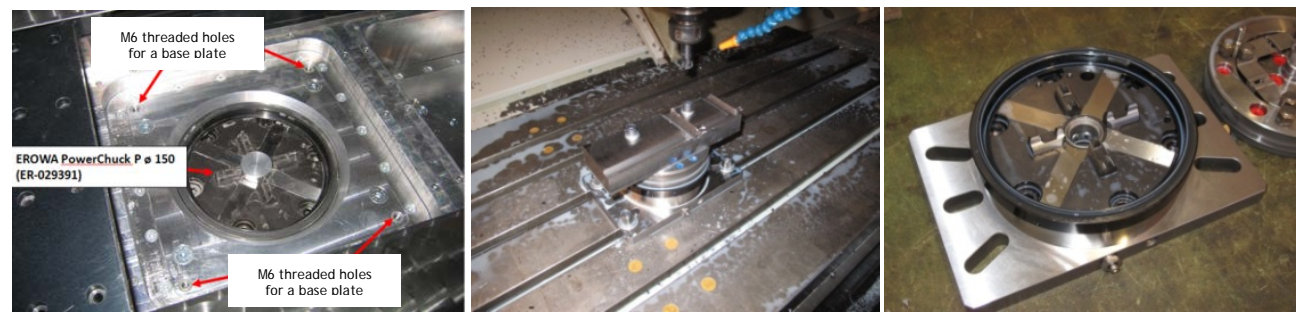

Figure 7: EROWA power chuck installation in the M2, and cutting fluid flooding over the work piece and power chuck during milling experiments

Hence, the pallet and work piece must either be rinsed (meaning the dismounting of the work piece from the pallet, as well as a cleaning, and remounting) or the milling must be performed without cutting fluids. In the interests of minimising manual labour and maintaining precise positioning, the latter alternative would be preferable.

In relation to the hybrid manufacture of injection moulding inserts, the base part material is fundamentally important. The base part material must be heat treatable to the required hardness, and be able to withstand the tensions of AM building without fracturing due to residual stress, and have good milling properties, preferably for dry milling. Three different steels have been evaluated for this purpose: a traditional injection moulding tool steel (Orvar Supreme by Uddeholm [15]), a maraging tool steel identical to ConceptLaser's tool steel powder (DIN W.nr. 1.2709 by Dörrenberg [17]), and a tool steel normally used for aluminium pressure die casting moulds (Marlok C1650 by Metso [18]). It was concluded that even if W.nr. 1.2709 is identical to the AM material, the milling properties were considerably worse than those of Orvar and Marlok, both of which had generally good milling properties, including dry milling. However, since Orvar requires a heat treatment at $1020-1030^{\circ} \mathrm{C}$, while the AM material is a maraging steel that requires a heat treatment at $490^{\circ} \mathrm{C}$, the use of Orvar for base material would require a hardening operation between the milling and AM building. By contrast, Marlok shares maraging properties with the AM tool steel, which means that the heat treatment of the inserts can be finished in a single operation after the AM building and before the finishing milling. So Marlok has been found to be the preferred material in the continuing development of the hybrid manufacturing cell for injection moulding inserts.

\section{CONCLUDING REMARKS AND FURTHER WORK}

Hybrid manufacturing has many merits that make it an attractive alternative in manufacturing high performance products. The combination of AMT and conventional technology enables the advantages of each process to be exploited where they are most beneficial. However, AM and traditional subtractive machining are fundamentally different and have different process requirements. Moreover, the increased number of manufacturing process steps increases the complexity of the process, and thus the need to control the various process conditions. In response to this, a project has been launched that aims to develop an integrated hybrid manufacturing cell. Even though the concept and working principle of the hybrid manufacturing cell are under development and are being continuously refined, the present investigations and evaluations have confirmed the feasibility of the project, while indicating that significant advantages can be gained from this system rather than the common solution to hybrid manufacturing in use today. Until now, development has primarily been aimed at compatible hardware functionality (such as positioning and clamping systems), and at minimising intermediary operations in order to manufacture injection moulding tool inserts. Further development includes a system for an 
optimising manufacturing operation sequence (OMOS) within the hybrid cell, as well as an integrated control system that enables communication between the machine units, thereby resulting in a higher degree of automation for the hybrid manufacturing process.

\section{ACKNOWLEDGEMENTS}

The development of the hybrid manufacturing cell is supported through collaboration among several national and international research projects and research programmes. The $7^{\text {th }}$ FP EU project IC2, "Intelligent and Customized Tooling" (NMP-2009-4.0-5, Grant agreement no. 246172), NFR (Research Council of Norway) project HYPRO, and the CRI Norman (Centre for Research Driven Innovation) have all contributed to the progress achieved thus far.

\section{REFERENCES}

[1] Karunakaran, K.P., Suryakumar, S., Pushpa, V. \& Akula, S. 2010. Low cost integration of additive and subtractive processes for hybrid layered manufacturing, Robotics and ComputerIntegrated Manufacturing, 26 (5), 490-499.

[2] Kerbrat, O., Mognol, P. \& Hascoet, J.Y. 2011. A new DFM approach to combine machining and additive manufacturing, Computers in Industry, In press, corrected proof, available online 6 May 2011.

[3] Hu, Z., Lee, K. \& Hur, J. 2002. Determination of optimal build orientation for hybrid rapid prototyping, J ournal of Materials Processing Technology, 130-131.

[4] Hedges, M. \& Calder, N. 2006. Near net shape manufacture \& repair by LENS®, AVT-139/ RSM019. NATO Research and Technology Organization RTO-MP-AVT-139AC/ 323C(AVT-139)TP/ 105.

[5] LaserCusing. nl. http:// www. lasercusing. nl/ content. php/ en/ 270. Accessed $26 \mathrm{~J}$ anuary 2012.

[6] Optomec. http:// www.optomec.com/. Accessed 26 J anuary2012.

[7] POM Group Inc. http:/ / www. pomgroup. com/ . Accessed 26 J anuary 2012.

[8] Sciaky Inc. http:/ / www. sciaky. com/. Accessed 26 J anuary 2012.

[9] Beaman, J.J. et al. 2007. WTEC panel report on additive/subtractive manufacturing research and development in Europe, 17-18, World Technology Evaluation Center. Inc. Baltimore, Maryland, USA:

www. dtic. mil/cgi-bin/ GetTRDoc?Location=U2\&doc=GetTRDoc. pdf\&AD=ADA466756. Accessed 26 J anuary 2012.

[10] Hur, J., Lee, K., Zhu-hu, \& Kim, J . 2002. Hybrid rapid prototyping system using machining and deposition, Computer-Aided Design 34.

[11] Kerbrat, O., Mognol, P. \& Hascoet, J.Y. 2008. Manufacturing criteria in hybrid modular tools: How to combine additive and subtractive processes, Virtual and rapid manufacturing, ISBN 978-0415-41602-3.

[12] Mognol, P., Jégou, L., Rivette, M. \& Furet, B. 2006. High speed milling, electro discharge machining and direct metal laser sintering: A method to optimize these processes in hybrid rapid tooling, Int. J ournal of Advanced Manufacturing Technology 29.

[13] Mognol, P., Rivette, M., Jégou, L. \& Lesprier, T. 2007. A first approach to choose between HSM, EDM and DMLS processes in hybrid rapid tooling, Rapid Prototyping J ournal 13 (1).

[14] Rännar, L.E. 2008. On optimization of injection molding cooling, Doctoral thesis, Norwegian University of Science and Technology, NTNU 2008:113, ISBN 978-82-471-8270.

[15] Uddeholm material data sheets. Orvar Supreme.

http:/ / www. uddeholm.com/ files/ PB orvar_supreme_english. pdf. Accessed 26 J anuary 2012.

[16] EROWA product data sheets.

http:/ / www. erowa.com/ en/ products/ workholding-systems/ prodnav/ PPM-

Standardization/ power-chuck-p/ powerchuck-p-chucks. html. Accessed 26 J anuary 2012.

[17] Dörrenberg material data sheets. Cold working tools steels, 1.2709.

http:/ / www. doerrenberg. de/ fileadmin/template/ doerrenberg/ stahl/ 1.2709_deu.pdf. Accessed 26 J anuary 2012.

[18] Metso Materials Technology. Product data sheets, Marlok C1650.

http:/ / www. metsomaterialstechnology.com/ MEP/ info. nsf/ WebWID/ WTB-081114-22574E9F9E/ \$File/ Marlok\%20brochure\%202008. pdf. Accessed 26 J anuary 2012. 